\title{
Media coverage of mercury contamination in the Canadian Arctic
}

\author{
Amanda D. Boyd ${ }^{1}$, Michelle L. Fredrickson ${ }^{1}$ \& Chris M. Furgal ${ }^{2}$ \\ ${ }^{1}$ The Edward R. Murrow College of Communication, Washington State University, Pullman, WA, USA; \\ ${ }^{2}$ Indigenous Environmental Studies and Sciences Program, Trent University, Peterborough, Canada
}

\begin{abstract}
Mercury contamination in the Canadian Arctic is a significant concern. Some traditional food sources are contaminated by mercury and pose a health risk to local residents. Media can affect public awareness and opinions of environmental health risks. Therefore, it is important to understand how the risks associated with contaminants are communicated through the media. To better understand how the issue of mercury contamination in the Arctic has been presented in the media, a content analysis was conducted across 14 newspapers in the Canadian North and South. We examined how news sources presented the health risks of mercury in the Arctic, how mercury was defined, if pathways for self-efficacy (i.e., how a person can reduce his or her exposure to a hazard) were provided and who was quoted as an information source. Results demonstrate that few Indigenous people were cited as information sources, articles often failed to describe mercury to the reader and many did not provide direction to support self-efficacy. This study provides insight into how newspapers have communicated about mercury in the Canadian Arctic and suggests specific ways that this communication can be improved.
\end{abstract}

To access the supplementary material, please visit the article landing page

\section{Introduction}

Mercury contamination continues to present risks to both human populations and wildlife in the Arctic. The accumulation of mercury in wildlife is of particular concern to Indigenous residents of the Arctic who rely on some species as traditional foods that are harvested or gathered from the local environment. Traditional foods include items such as seal, whale, walrus, fish, caribou and local berries (Lougheed 2010). Traditional foods are not only an important part of a northern diet, but are also linked to cultural and spiritual well-being (Donaldson et al. 2005).

Arctic residents who consume large amounts of fish or mammals may be exposed to higher levels of mercury (AMAP 2011). There is an increasing need for public health officials to communicate about the risks of contaminants to vulnerable populations to support their informed decision-making about diet and health. Those residing in southern regions of Canada should also be aware of contaminants in the Arctic, as they may also contribute to policy and public discourse on the issue.

Communication about contaminants in the Arctic presents numerous challenges and there is still much to learn in order to effectively communicate about these environmental health risks. The fact that mercury is an invisible, tasteless, odourless and ongoing hazard for Arctic populations continues to challenge public health officials in the development and delivery of risk messages. An important step in improving the delivery of health messages is to assess and evaluate how the media presents information about a hazard (Lundgren \& McMakin 2013). Mass media is an information source that the public draws from when constructing perceptions, opinions and reactions to a hazard (Corbett $\&$ Durfee 2004). This is particularly true of risks that are relatively unknown or poorly understood by the affected general population (Fleras 2003). This may be the case in the Canadian Arctic, as numerous studies 
have reported a low awareness and limited understanding about mercury exposure in the North (Kinloch et al. 1992; Usher et al. 1995; Myers \& Furgal 2006). While the media may influence risk perceptions in northern regions, it also plays a role in the formation of southern populations' opinions of Arctic issues. People in the South have little direct experience with Arctic circumstances and events (Greenberg 2002). Therefore, southern populations often rely on the media for information about Arctic issues (Pincus \& Ali 2016). Despite the fact that the media plays an important role in presenting Arctic issues, there have been few studies that have explored media treatment of Arctic issues to date (Pincus \& Ali 2016). It is especially important for public health officials to understand how the media portrays health risks (Green 2004; Lundgren \& McMakin 2013). Public health officials have an important responsibility to communicate about health risks (Regidor et al. 2007; American Public Health Association 2011), including the risks associated with mercury exposure (Pirkle et al. 2015). Public health officials can use this information to gain insight into what the public may or may not have heard about a risk and ultimately develop more informed health messaging to either counteract incorrect reporting or build on appropriate media reporting (Institute of Medicine 2003).

Newspapers are one form of media that southern populations (Jardine et al. 2015) and Arctic residents use to seek information about health risks (Boyd et al. 2011). For example, a study of residents in two communities in the Northwest Territories found that over half of participants used newspapers to find information about health risks (Boyd et al. 2011). A newspaper content analysis can therefore provide insight into how information about important Arctic issues, such as mercury contamination and its potential risks for Canadian Arctic residents, is presented to the public. We conducted a content analysis across 14 newspapers in the Canadian North and South. This study has four primary research objectives. The first is to assess how the media defines mercury and describes who is affected by mercury exposure. The second objective is to examine the general tone of the articles. The third objective is to appraise if newspaper articles provide mitigation strategies or means by which individuals can reduce their mercury contamination and exposure. The final objective is to examine who writes the articles and what is cited as information sources in the news coverage. This study assesses how newspapers have communicated about contaminants to the Canadian public in the North and South and ultimately may help the public health community understand and anticipate challenges in communicating about contaminants.

\section{Background}

\section{Mercury: an international problem}

Mercury is a naturally occurring element that exists throughout the world. It can be found in rock and soil and can be taken up by vegetation and therefore occurs naturally in some plants and trees. When disturbed by natural (e.g., forest fires, volcanic eruptions) or anthropogenic (e.g., mining, burning of coal in coal-fired power plants) processes, mercury can be released into the air and water (UNEP 2013). Leading sources of anthropogenic dispersion of mercury include coal-fired power plants, mining activities, oil refining and cement production, as well as smelting and iron production (AMAP 2011 ). The regions releasing the greatest amounts of mercury into the environment through anthropogenic processes include the US East Coast, India, China and some areas in South America (UNEP 2013). Once released, this heavy metal can travel from its site of dispersion via atmospheric and oceanic currents to distant and remote geographic locations (UNEP 2013). Most anthropogenic mercury found in the Arctic does not originate there and Arctic populations do not significantly contribute to mercury releases into the environment.

Once in aquatic environments, mercury can be transformed by microbes from its inorganic form into an organic form that is toxic to living organisms (EPA 2016). This form of mercury, known as methylmercury, will not degrade and is a neurotoxin that is hazardous to humans and animals (UNEP 2013). In the Arctic, methylmercury enters the food chain when predators eat smaller prey species that contain this toxic form of mercury (AMAP 2011; EPA 2016). Mercury concentrations are therefore magnified in the food chain as one moves up from prey species to predator species. As a result, older predator species at the top food chains typically contain the highest concentrations of methylmercury. In the Arctic, many Indigenous communities perform subsistence activities, including hunting, fishing and gathering food resources from their local environment, to acquire a significant portion of their diet. Some of these traditional foods expose Indigenous people living in these environments to methylmercury (Van Oostdam et al. 2005).

\section{Mercury exposure in the Canadian Arctic}

The Arctic encompasses over $40 \%$ of the landmass of Canada and is home to more than 200000 Canadians (Government of Canada 2019). The Canadian North includes the three territories of Canada: Yukon, Northwest Territories and Nunavut. It also includes the northern region of the provinces of Québec (Nunavik) 
and Labrador (Inuit Settlement Area of Nunatsiavut). Indigenous populations (including Inuit, First Nations and Métis) comprise the largest population group in the Canadian Arctic (Indigenous and Northern Affairs Canada 2016).

Elevated levels of mercury have been discovered in many areas of the Arctic environment. Many individuals residing in Nunavut have blood concentrations of mercury exceeding the acceptable 20 ppb level set by Health Canada (Chan 2011). Research from the 2007-08 Inuit Health Survey, gathering information on health and well-being in three of the four Inuit regions in the Canadian Arctic, found that $43 \%$ of Inuit women of childbearing age in Nunavut had mercury blood concentrations above $8 \mathrm{ppb}$, the safety guideline for this group (Chan 2011). In Nunavut, the primary source of mercury in the Inuit diet is ringed seal (Phoca hispida) liver (Chan 2011). The liver contains higher levels of mercury than the muscle of the animal because it filters toxins from the blood and therefore accumulates the contaminant in the animal (Chan 2011). Women of childbearing age and pregnant women in this region have been advised by agencies such as Nunavut's Department of Health to eat ringed seal meat instead of ringed seal liver to minimize exposure and potential negative impacts on the developing foetus (Chan 2011).

In Nunavik, $72 \%$ of women of childbearing age have higher than the government-recommended amount of mercury in their blood (Lemire et al. 2015). The primary sources of mercury exposure in Nunavik include consumption of dried beluga (Delphinapterus leucas) meat and certain types of fish such as lake trout (Salvelinus namaycush) (Lemire et al. 2015). Women of childbearing age in this region have been advised to reduce their consumption of beluga meat to avoid negative impacts on their health and that of the developing foetus (Nunavik Regional Board of Health and Social Services 2011).

In the Northwest Territories, health advisories have warned about rising mercury levels in fish in some freshwater lakes. Since 2007, health advisories have been issued for numerous lakes in the territory (see NWT 2007-2012). These advisories recommend limiting fish consumption from certain lakes, specifying the species, to recommended amounts per week deemed safe to eat (NWT 2007-2012). The various health advisories presented in the Northwest Territories and other Arctic regions demonstrate that mercury contamination is a human health issue that impacts numerous northern regions and populations.

\section{Complexities of communicating about contaminants and importance of traditional foods}

The challenges of communicating about mercury exposure in the Canadian Arctic are complex (Furgal et al. 2005).
Contaminants such as mercury are invisible and tasteless; most emissions into the environment do not originate in the region, yet they are a contemporary hazard for Arctic populations. Public health organizations have attempted to deliver messages about the health risks associated with exposure to environmental contaminants via consumption of traditional foods as well as the nutritional benefits associated with these same foods to Arctic Indigenous populations, yet sometimes these messages have been met with disbelief or confusion (McAuley $\&$ Knopper 2011). For example, Myers $\&$ Furgal (2006) examined the awareness of messages about traditional foods and contaminants, as well as Inuit attitudes towards traditional food in Nunavut and Labrador. Results demonstrate that the majority of respondents had heard about the issue of contaminants in traditional foods; however, many were unable to state what they thought a contaminant was, or their explanations included substances other than the chemical or natural components typically used in the definition of contaminants (e.g., they mentioned rusted metal, sealskins left on the beach). Many respondents were not aware that the impact of mercury exposure to pregnant women was particularly harmful because of the negative effects to themselves and their developing foetuses. In addition, respondents in Nunavut and Labrador differed in their attitudes towards contaminants. Most participants in Nunavut said that they would never change their food habits because of contaminants, whereas the majority of Labrador respondents said that they would make changes to their food habits. These studies, among others (e.g., McAuley \& Knopper 2011), demonstrate that there may be regional differences in comprehension of contaminants and assumptions of personal exposure.

Communicating about contaminants is especially challenging because of the importance of traditional foods for many Indigenous populations. Traditional foods are linked to cultural and spiritual well-being, as well as being an important part of an Arctic diet. Further, food insecurity rates are high in many regions of the Arctic. For example, Nunavut reports the highest level of household food insecurity among an Indigenous population outside the developing world (Council of Canadian Academies 2014). The amount of traditional foods consumed varies by many factors, including season and geographic region (Blanchet 2008). The fact that traditional foods (or parts of traditional foods) that are available to local Arctic populations may have high levels of mercury creates a difficult situation for many Arctic people because other (safer) food choices may be less available in these regions. They may be less available for several reasons: there may be fewer local food sources that are low in contaminants but still high in needed nutrients in the area, 
local food-storage may not be readily accessible, or food costs may be exorbitantly high at local stores.

It is therefore important that effective communication messages and strategies are developed to inform people about both the risks and the benefits of consuming traditional foods. There have been cases where attempts at communicating about contaminants have led to a shift away from traditional foods, which has been reported to have negative economic and health impacts on Indigenous people residing in the Canadian Arctic (Usher et al. 1995; Furgal et al. 2005; Myers \& Furgal 2006; Krümmel \& Gilman 2016). Results from these past studies conclude that communicating about contaminants is difficult and complex and further studies are needed to determine the most effective methods to communicate about mercury exposure.

\section{Theoretical background: framing effects and self-efficacy}

In this section, we provide the research questions (RQ) for the study and an overview of our theoretical background. To develop effective risk messaging and health communication campaigns, it is necessary to understand how hazards are presented to the public (Slovic 2000). Print media analysis is a method that is used to better understand how hazards are presented to an audience (Dunwoody 1992; Friedman \& Dunwoody 1999). Research indicates that content analysis of newspapers can be used to anticipate which hazards the public may be concerned about (Friedman \& Dunwoody 1999), and how the public may react to a hazard (Newig 2004). The research presented in this newspaper content analysis examines how risks are communicated to the public and how (or if) direction to support self-efficacy (i.e., information about how a person can reduce his or her exposure to a hazard) is presented to the public as this information could impact the actions of those living in northern and southern Canada.

Media framing refers to the way in which information is presented. Frames can be created by the inclusion or omission of words, phrases, imagery, stereotypes, facts or details (McQuail 2002). The use of frames by the media may highlight certain aspects of a subject or increase the likelihood that an audience may perceive information in a particular way (Fleras 2003). Frames can reinforce existing points of view by drawing attention towards some elements and away from others (Fleras 2003). Through media framing, we can hypothesize that the way in which information is presented in the media will impact the way readers perceive that information (Scheufele $\&$ Tewksbury 2007). Studies have found that the way a health risk is framed can influence risk perceptions and risk mitigation behaviours (Rothman \& Salovey 1997).
The influence of how a risk is perceived is tempered by other factors such as prior risk perceptions and knowledge about a hazard (Rothman \& Salovey 1997).

Past studies have successfully examined how newspapers frame contaminants issues to better understand media representations of the risk (see, e.g., Griffin $\delta$ Dunwoody 1997; Greiner et al. 2010; MacKendrick 2010). It is therefore critical to assess how newspaper articles portray mercury by assessing what information is included or omitted in the newspaper coverage. This will create a better understanding of what the audience may have heard about a risk. We examine how mercury is presented in newspaper articles with specific attention on the definition or description of mercury used, human health impacts identified and exposure pathways reported (RQ1).

Furthermore, this research expands upon work from Scheufele \& Tewksbury (2007) by examining the tone of the article-whether the article has an optimistic, neutral or pessimistic tone. Research has found that health articles that use a pessimistic tone and fail to provide direction for self-efficacy may cause people to feel powerless (Rothman \& Salovey 1997). Perceived self-efficacy can be defined as a person's beliefs in their ability to influence the events that impact their lives (Weiner \& Craighead 2010). Bandura (1977) explains that expectations of personal mastery will affect the initiation of coping behaviours. People may be more likely to get involved in activities (e.g., risk mitigation actions) when they think that they can effectively handle or control a situation (Bandura 1977, 1997). Research has found that providing information about self-efficacy may produce greater rates of willingness to take actions to avoid a hazard (Neuwirth et al. 2000). A Canadian media content analysis about contaminants concluded that self-protection information may lead to more empowered individuals, who are more willing to reduce their exposure to a hazard (MacKendrick 2010). Therefore, we expand upon past research on tone and self-efficacy to examine the tone of the articles that focus on mercury contamination (RQ2) and if avenues for self-efficacy are provided in news stories about mercury in the Arctic (RQ3).

It is also important to assess who is cited as an information source in an article (Lundgren \& McMakin 2013). Studies show a lack of Indigenous and minority voices in health reporting in the media (Hodgetts et al. 2008). As many people make health decisions based on media coverage (Brodie et al. 1999), researchers argue that the lack of minority-relevant health information is problematic and may be addressed through greater inclusion of minority voices in sourcing (Brodie et al. 1999; Kurpius 2002). As studied by Meier et al. (2017), inclusion of 
specific voices and stories of the people most impacted by a problem is more effective at increasing awareness and caring about that problem than simple statistics, no matter how drastic the statistics may be. Specifically, when a humanitarian or health crisis is involved, the population at-large tends to become more empathetic and emotionally invested in stories with a human factor showing the impact (Meier 2017; Slovic et al. 2017). Therefore, inclusion of Indigenous voices in reporting on mercury contamination in the Arctic may be useful both for civic journalism (Kurpius 2002; Hodgetts et al. 2008) and for increasing empathy among readers (Meier 2017; Slovic et al. 2017).

Furthermore, studies demonstrate that when readers perceive similarity between the source and themselves, their ratings of respect and trust in the source also increase (Kreuter \& McClure 2004). The source could include the author or sources cited within the document (Kreuter \& McClure 2004). It has also been suggested that when there is greater perceived similarity between source and receiver, the reader may be more willing to follow advice given (Clyne \& Clyne 1996). This could theoretically impact Arctic populations' risk mitigation behaviours should they engage with an article where the information source is also an Indigenous person or organization residing in the Arctic. Therefore, we assess information sources in news coverage of mercury contamination in the Canadian Arctic (RQ4). In particular, we examine if Indigenous populations are cited as sources of information in articles about Arctic mercury contamination.

\section{Methods}

This study employs a media content analysis to examine Canadian newspaper coverage of mercury contamination in the Arctic. Newspapers can be a source of information and a significant way people educate themselves about important risk issues (Altheide \& Schneider 2013). The media examined in this study include: (1) all newspapers located in Canadian Arctic regions, (2) six large southern regional newspapers, and (3) one leading national newspaper (see Table 1 for summary of newspapers analysed). In the third category, The Globe and Mail was selected because it is one of the primary national papers in Canada and is available to the entire Canadian population. However, The Globe and Mail also often focuses on news from Ontario (Driedger et al. 2009). The six regional papers were included as they represent locations throughout Canada including the provinces of British Columbia, Alberta, Manitoba, Ontario, Quebec and Newfoundland and Labrador. Greiner et al. (2010) recommend examining articles about contaminants throughout different regions because there can be regional variation in risk events, histories and perspectives about contaminants.

The keyword "mercury" was used to search for articles discussing mercury contamination in the Arctic. All articles were collected from original online newspaper archives between 1 January 2006 and 31 December 2015. A 10-year search period was used to ensure coverage during numerous events such as the release of the results from northern health studies, such as the Inuit Health Survey, and attempts to create global agreements

Table 1 Newspaper sources.

\begin{tabular}{|c|c|c|c|}
\hline Region & Newspaper & Origin of publication & Circulation \\
\hline \multirow[t]{8}{*}{ Northern } & Nunatsiaq News & Iqualuit, NU & unknown \\
\hline & Northern News Servicesa & Yellowknife, NT & \\
\hline & NWT News/North & Yellowknife, NT & 7779 \\
\hline & Yellowknifer & Yellowknife, NT & unknown \\
\hline & Nunavut News/North & Iqualuit, NU/ Yellowknife, NT & 6127 \\
\hline & Kivalliq News & Rankin Inlet, NU & unknown \\
\hline & Deh Cho Drum & Fort Simpson, NT & unknown \\
\hline & Inuvik Drum & Inuvik, NT & unknown \\
\hline National & The Globe and Mail & Toronto, ON & 291571 \\
\hline \multirow[t]{6}{*}{ Southern regional } & Edmonton Journal ${ }^{\mathrm{b}}$ & Edmonton, $\mathrm{AB}$ & 96234 \\
\hline & The Telegram ${ }^{c}$ & St. John, NL & 24311 \\
\hline & The Star & Toronto, ON & 381310 \\
\hline & Winnipeg Free Press & Winnipeg, MB & 125000 \\
\hline & Vancouver Sun ${ }^{d}$ & Vancouver, BC & 156158 \\
\hline & Montreal Gazette & Montreal, QC & 116446 \\
\hline
\end{tabular}

\footnotetext{
a The Northern News Services retained the archives for the NWT News/North, Yellowknifer, Nunavut News/North, Kivalliq News, Deh Cho Drum and Inuvik Drum. Archives could not be separated into the six individual newspapers.

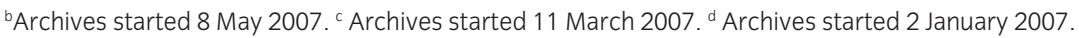


to reduce mercury, such as the Minamata Convention. In 2013, the United Nations passed the Minamata Convention on Mercury and a legally binding international protocol was developed and implemented to decrease global mercury emissions and slow its adverse health and environmental impacts (UNEP 2013). The articles that mentioned mercury went through a screening process and were included in a full analysis if the article fulfilled the following criteria: (1) it was about the heavy metal mercury (rather than mercury related to vehicles, weather, horoscopes, etc.); and (2) it discussed the Arctic (the article did not need to include the specific word "Arctic" to be included in the media analysis but had to discuss a region of the Arctic.) Any article type (e.g., business, lifestyle), including letters to the editor, that met the two criteria were included in the analysis. A total of 81 articles met the requirements and were further analysed.

Retained articles were analysed for numerous aspects. Firstly, we examined if newspapers provided a definition and description of mercury (RQ1). We examined if articles stated that mercury is harmful, harmless or both, as well as what was the identified original source of mercury (including location and industry). We also examined if newspapers described who was affected and how they were exposed. A description of the final coding variables for all RQs is provided in Table S1.

We also examined the tone of the article (RQ2). Tone was measured using a three-point scale of optimistic, pessimistic or neutral, consistent with research by Collins et al. (2006). An article was classified as "optimistic" if it discussed the hazard in a way that was hopeful, assuring, calming or assuaging overtly negative concerns. An article was defined as "pessimistic" if it supported negative interpretations of the content or did not attempt to ease potential negative emotions a reader may acquire from the article content. The article was classified as "neutral" if the article made no judgement about the risk, was ambiguous or if there were relatively equal numbers of optimistic and pessimistic attributes. We also examine if newspaper articles provided solutions or mitigation strategies (such as not eating certain animals or animal parts or avoiding fish from certain lakes) to reduce mercury exposure (RQ3).

Finally, we examined who wrote the articles and who were cited as information sources (RQ4). Article authors included local journalists, wire services and others. For sources cited, we examined if newspapers cited scientists, government representatives, Indigenous organizations or authorities, members of the general Indigenous population, the general non-Indigenous public, doctors or other public health officials.

One researcher was primarily responsible for collecting articles from the 14 newspapers. If it was unclear whether an article should be included, this was discussed between the researchers to determine final inclusion or exclusion. To ensure accuracy of article characterization, researchers performed an intercoder reliability test. Two of the authors independently categorized a selection of $20 \%$ of the articles $(n=16)$. Agreement between coders was calculated using Cohen's kappa to establish reliability. "Moderate" agreement between coders was indicated by a Cohen's kappa of 0.60-0.79 (McHugh 2012). "Strong" agreement between coders was indicated by a Cohen's kappa of 0.80-0.90 (McHugh 2012). Cohen's kappa for this subset ranged from 0.78 (lowest Cohen's kappa was for tone of the article) to 1.0. Any abnormalities or apparent contradictions were discussed and a consensus was built and used to make a final decision. This process served to verify the integrity of the analytical process (Guest et al. 2006).

\section{Results}

\section{Description of articles}

There was a total of 10424 articles in the 14 newspapers that mentioned the word "mercury" appearing between 1 January 2006 and 31 December 2015. A total of 81 of these articles focused on mercury contamination in the Canadian Arctic. The seven northern news sources produced 58 articles and the seven southern papers (including the six regional and one national news source) produced 23 articles (Table 2). There was an average of six articles on mercury contamination per year. The years that had the most articles on mercury in the Arctic were 2010 and $2012(n=12)$, and the year with the fewest number of articles was $2006(n=2)$ (Fig. 1).

Articles varied in the way they described mercury, as something that is harmful, harmless or both. As mentioned earlier, there are many complexities that contribute to the challenges of communicating about mercury

Table 2 Number of articles by newspaper.

\begin{tabular}{lcc}
\hline News sources & $\begin{array}{c}\text { Total number of } \\
\text { relevant articles }\end{array}$ & $\begin{array}{c}\text { Total number of articles } \\
\text { with keyword "mercury" }\end{array}$ \\
\hline Northern News Services $^{\text {a }}$ & 31 & 209 \\
Nunatsiaq News Online & 27 & 184 \\
The Globe and Mail & 7 & 5560 \\
Winnipeg Free Press & 7 & 2369 \\
The Star & 3 & 1532 \\
Montreal Gazette & 0 & 205 \\
The Telegram & 5 & 195 \\
Vancouver Sun & 0 & 172 \\
Edmonton Journal & 1 & 124 \\
\hline
\end{tabular}

a Individual newspapers listed in Table 1. 


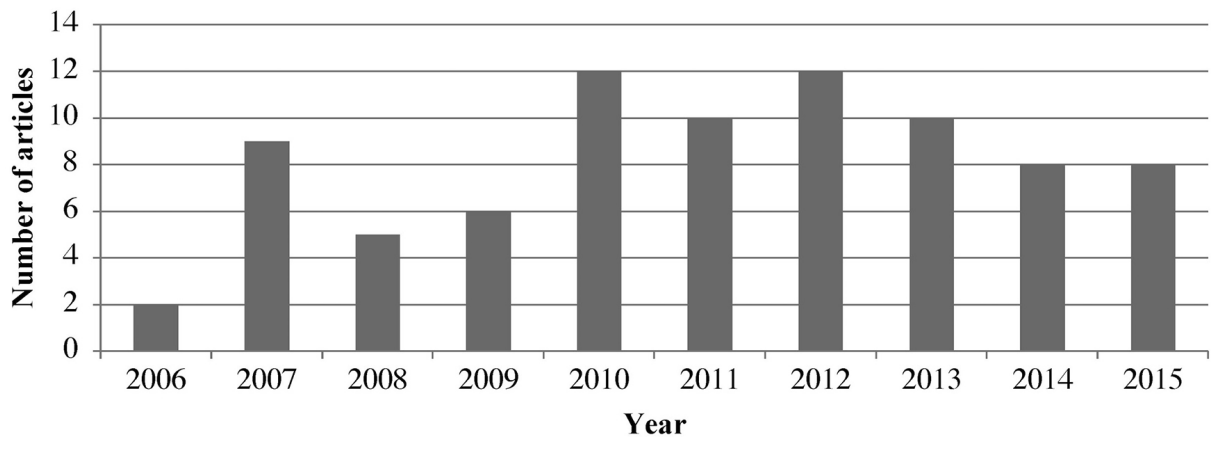

Fig. 1 Relevant articles by year. Potentially significant events discussed in the article include the Minamata Convention on Mercury in 2013 and the Nunavut Inuit Health Survey completed between 2007 and 2008.

contamination. Among them, it is the fact that mercury, which can take several chemical forms (of which methylmercury is deleterious to organisms), occurs naturally in the environment but can also be amplified in concentrations and locations where it is found via anthropogenic activities (NWT 2016). In the articles analysed, in most instances, mercury was described as something toxic or harmful, such as a "potent neurotoxin" or "toxic heavy metal." Other articles described mercury as something that is not a concern. Some articles described it as both harmful and harmless. For example, an article in Nunatsiaq News described mercury as a "relatively harmless inorganic form of the chemical mercury" that changes into "a potent neurotoxin when it's in seawater" (Anonymous 2011).

The majority $(n=53)$ of articles did not discuss the source of the mercury contamination. Of the articles that discussed the source, 27 were from the northern newspapers, and nine were from southern newspapers. With regard to specific regions or countries (an article could assign the source of mercury to more than one region or country), five articles vaguely stated the source of mercury as being from "the south." In nine articles, Asia was discussed as the source of mercury, and in five of the nine articles, it was specified further to China. Two articles stated that the United States was the source of mercury contamination and six articles stated that the source was "southern Canada," with four of these six articles specifically mentioning that Muskrat Falls, a proposed hydroelectric dam, could be a future source of mercury. A total of 16 articles cited industries (e.g., coal-fired power plants, cement manufacturing plants, hydroelectric dams) as the source of the mercury. Some articles simply stated that the Arctic was not the source of contamination. The following statement is an example of a description of the source of mercury: "despite a lack of industrial activity, the Arctic receives mercury from atmospheric pollution from all over the world. Coal-fired power plants are considered to be the prime source of mercury pollution, with China, which relies heavily on coal, the worst offender" (Zarate 2010).

A total of 45 northern and southern articles described who was affected by mercury contamination. Results indicate that the most common group described to be impacted by mercury exposure was "Inuit" $(n=24)$ in general, followed by "women of childbearing age" $(n=20)$ (Fig. 2). The way in which people were exposed to mercury was discussed in 64 articles. All of these articles stated that mercury exposure occurred when people consumed contaminated traditional foods.

\section{Tone of articles}

There were relatively equal numbers of articles among the optimistic $(n=28)$, pessimistic $(n=29)$ and neutral categories $(n=24)$ (Fig. 3). An example of an article in Nunatsiaq News that had an overall optimistic tone summarized the problem as follows:

... researchers have encouraged Nunavik public health and other regional authorities to encourage the consumption of country food among Nunavimmiut in order to improve the region's maternal health and child development. One way to do that is through a regional food policy, researchers say, which could promote the benefits of country food and help residents have better access to it. (Rogers 2011)

An example of an article with an overall pessimistic tone discussed mercury as follows: “Despite growing concerns over mercury contamination in northern fish, lakes around Yellowknife remain untested for the toxic substance and will remain so until someone steps forward with a proposal to test them" (McMilliam 2010). Of the 28 optimistically framed articles, 24 and four were in northern and southern papers, respectively. In contrast, 


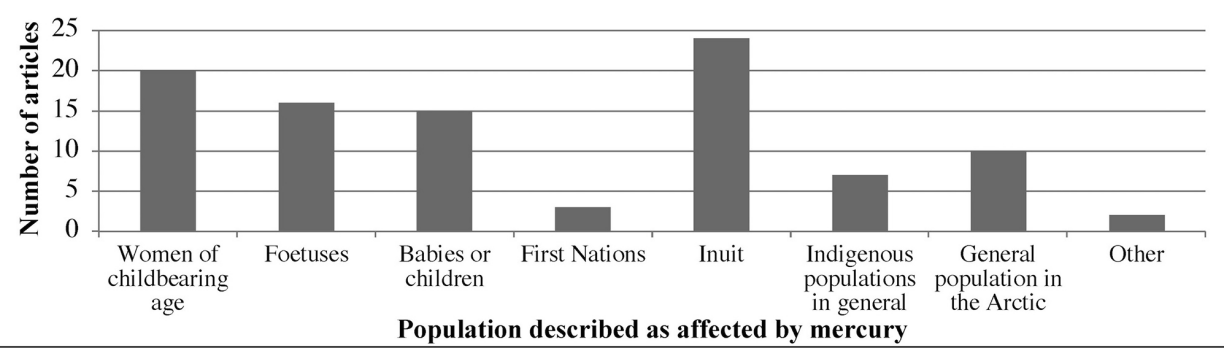

Fig. 2 Populations described as affected by mercury. Articles may suggest that more than one population can be affected by mercury exposure (e.g., Inuit women of childbearing age). In this case, both categories of 'Inuit' and 'Women of childbearing age' would be designated as present in the figure.

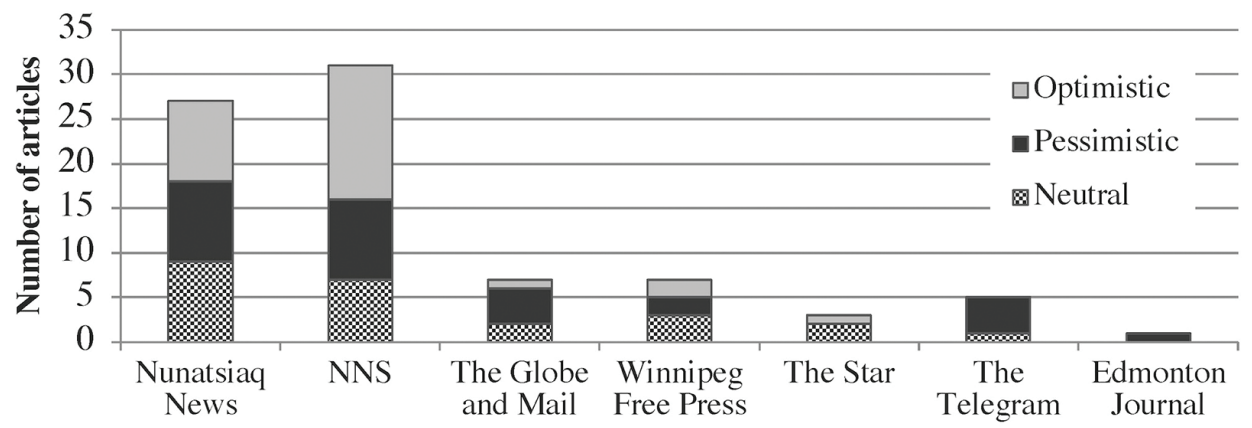

\section{News source}

Fig. 3 Tone of articles. Northern news sources include Nunatsiaq News and Northern News Services. Regional news sources include The Globe and Mail. Southern news sources included the Winnipeg Free Press, The Star, The Telegram and the Edmonton Journal.

the 29 pessimistically framed articles came from a wider range of newspapers: 18 from northern papers and 11 from southern papers. There was a total of 24 neutral articles-16 in northern papers and 8 in southern papers.

\section{Self-efficacy and mercury contamination}

A total of 22 articles $(27.2 \%)$ provided direction to support self-efficacy, that is, how to mitigate the risk associated with mercury exposure. Most of these articles were in northern papers (Nunatsiaq News $=9 ;$ NNS $=11$ ) and two were in a southern regional paper (Winnipeg Free Press $=2$ ). However, the majority of articles-61 in totaldid not provide any information about self-efficacy. Thirty-three articles in the northern papers and 28 in the southern papers did not discuss avenues for risk mitigation. None of the southern papers, except for the Winnipeg Free Press, discussed how the risk or issue of mercury contamination could be mitigated.

\section{Authors and sources cited}

The majority of the relevant articles in northern newspapers were written by a local journalist or were attributed to the newspaper without a journalist being identified as the author. Southern journalists also wrote most of the articles in the southern papers included in the analysis. However, southern sources also used content from wire sources, most notably the Canadian Press.

In both northern and southern newspapers, there was a general lack of Indigenous information sources. A total of 20 articles cited Indigenous organizations or authorities as information sources. For the purposes of this study, a representative of an Indigenous organization or and Indigenous authority could be an Indigenous or non-Indigenous person. A source was characterized as being an "Indigenous organization or authority" if the person was described as representing, or being affiliated with, an Indigenous people's organization. Only six articles cited people from the general Indigenous population as a source of information. Of the 20 articles that cited Indigenous organizations or authorities, most were in northern newspapers (NNS $=8$, Nunatsiaq News $=7$ ). Four articles from southern newspapers cited Indigenous organizations or authorities, including three in The Telegram and one in The Globe and Mail. No southern papers cited members of the Indigenous general population (see Fig. 4 for summary). The most common sources quoted 


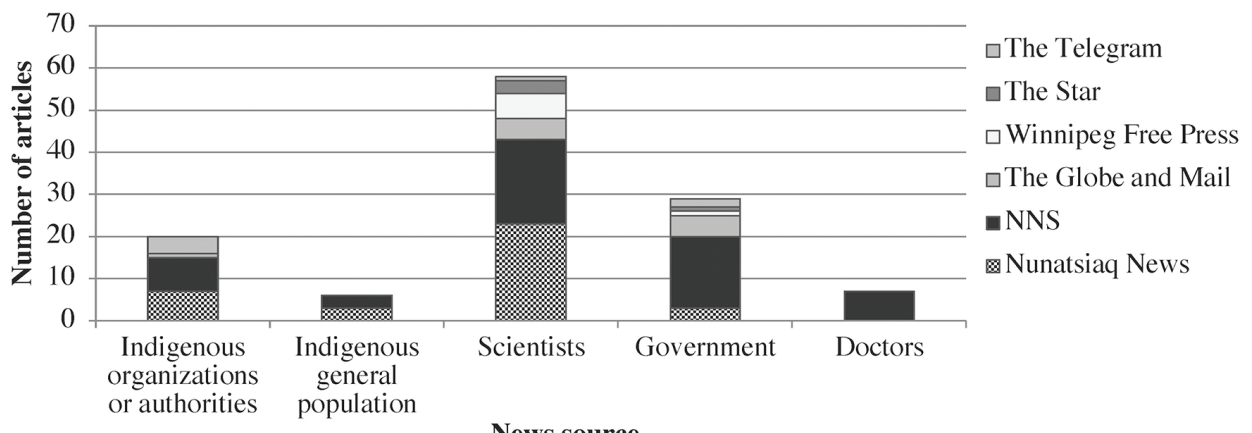

Fig. 4 Primary sources of information cited in articles. The Edmonton Journal is not included in this figure because the article did not cite any of these sources. The Vancouver Sun and Montreal Gazette are not represented because the newspapers did not have articles relevant to this study.

in newspaper articles about mercury in the Arctic were scientists, appearing in 43 of the 58 total northern articles and 15 of the total 23 southern articles. This may be in part due to the fact that most articles were about research on contaminants in the Arctic.

\section{Discussion}

Effective risk communication requires that public health officials who are charged with communicating about a hazard assess and evaluate media messages about the hazard. This will provide a better understanding how one dissemination channel portrays the risk to the public (Lundgren \& McMakin 2013). Our research provides insight into how mercury contamination is presented to populations in northern and southern Canada via selected newspapers. Four predominant findings from the media analysis are discussed further in this section. These findings include: (1) there is a dearth of articles published about mercury contamination, especially in southern Canadian newspapers; (2) the way mercury is discussed may be a source of confusion for the public; (3) the majority of articles did not provide direction to support self-efficacy and (4) few Indigenous people or organizations were cited as information sources in articles.

There were 81 articles presented in the 14 newspapers during the 10-year period examined. This can be considered a limited number of articles in comparison to the number of mercury advisories in the Arctic. To demonstrate this limited coverage, we searched the websites of two organizations in the Northwest Territories for mercury advisories, using the keyword "mercury." A search of the Northwest Territories Health and Social Services and the Department of Indian Affairs and Northern Development websites found 34 mercury advisories in the territory. While this is not a full analysis of mercury advisories in the Canadian Arctic, it provides an indication of the relative scarcity of newspaper articles in comparison to the number of advisories. There was also a numerical discrepancy in coverage of mercury contamination between the North and South, with the seven northern newspapers publishing two and a half times as much relevant content as the seven southern outlets. Even though mercury contamination is a global issue, not just a Canadian Arctic concern, the effects of mercury contamination in the Arctic do not have much day-to-day impact on the people in the south, which may contribute to the overall lack of media coverage in that region.

The way in which most articles tend to describe-or not-mercury as a contaminant could have implications for the public's understanding of the hazard. As previous research has outlined, communicating about contaminants is difficult (Sandman 1993). This can be particularly true about communicating about contaminants with Indigenous populations, such as the Inuit, because there is no accurate traditional Indigenous word for chemical contaminant (Furgal et al. 2005). The lack of description or definition of mercury in many of the articles could contribute to the public not fully understanding the issue, particularly because contaminants and pollution are fairly recent issues in the region. Research by Pincus \& Ali (2016) indicates that regional and collaborative decision-making about risks in the Arctic requires an informed public. Therefore, it is critical that those responsible for communicating about the risk unpack the complex nature of contaminants to provide clear and effective messaging, and empower people with the knowledge needed to mitigate the risk. In the case of contaminants in the Arctic, we would advise journalists to explain in their articles where to find more information about health risks, what mercury contamination is, who may be at risk and what contaminated and healthy traditional food alternatives are. 
Ultimately, the results of this study are consistent with other research on the challenges of communicating about contaminants. In their study about media representations of fish advisories, Greiner and colleagues conclude:

Given the progressive understanding of contaminants such as methylmercury alongside the growing scientific literature on the beneficial effects of omega- 3 fatty acids, voluminous and inconsistent health messages may in turn have an impact on consumer perception of risk and their resulting food choice behavior. (Greiner et al. 2010: 1792)

There were 22 articles that discussed avenues for risk mitigation. Only two articles in a southern newspaper provided any information promoting self-efficacy, and only one of those provided suggestions for what people in the South could do to help mitigate the problem. Examples of avenues for risk mitigation included consuming smaller or specific parts of animals, or not consuming specific species of fish or marine mammals. Furthermore, many of the pessimistic articles did not provide any information about risk mitigation behaviours. Of the total 29 pessimistic articles, only two provided suggestions for risk reduction behaviours. As indicated by Rothman and colleagues (2006), articles that use a pessimistic tone and fail to provide direction for self-efficacy may cause people to feel powerless.

The majority of articles did not provide suggestions or information about risk reduction behaviours. It is well recognized that if people feel powerless and no risk reduction strategies are provided, people are unlikely to take steps to reduce a risk (Yzer 2012). The challenge for journalists will be to interview people such as researchers or public health officials with knowledge of contaminants, and to report methods to mitigate risk or influence change in the area where the newspaper is disseminated. For example, in Nunavik, a reporter may need to discuss the risks of eating dried beluga meat, yet emphasize the benefits of other locally available traditional foods or nutritional programmes for women of childbearing age. This research and others (see for example Greiner et al. 2010) demonstrate the need for tailored information that provides avenues for risk mitigation from contaminant exposure.

Few articles originating in the South cited Indigenous organizations or authorities as information sources, and no southern newspaper cited anyone from the Indigenous general public in an article. Rather, most articles cited researchers as information sources. It is standard professional practice to contact researchers in order to bring objectivity and rigour to news stories (Angler 2017). However, the society for professional journalists includes calls in their code of ethics to "give voice for the voiceless" and to "seek sources whose voices we seldom hear" (SPJ 2014). This becomes increasingly important regarding citing Indigenous sources, particularly in coverage of an issue such as mercury contamination in the Arctic, where they are the primary people affected. Therefore, it is important to hear from those who are affected by a risk and also the scientists who conduct the research. Indigenous people were rarely quoted in the articles, but when they were included, they provided a rich understanding of what mercury contamination in traditional foods means for the day-to-day life of the people impacted by such contamination. For example, scientific experts were more frequently cited to explain biomagnification and bioaccumulation of mercury in marine food chains and traditional foods, while Indigenous people explained what this meant for their lives. In one article from Nunatsiaq News, an Inuk woman stated knowing about the dangers of mercury in ringed seal liver, but expressed her intent to continue eating it for other reasons:

"I eat ringed seal liver-it's a delicacy," said Elisapie Ikkidluak, who came to the feast. Ikkidluak, who said she was aware of the high level of mercury before the information session, isn't worried about the potential harmful effects of eating ringed seal liver. "If you don't eat ringed seal liver, you're going to freeze when you're out on the land, or out hunting. It strengthens the blood," Ikkidluak said. And in terms of taste, "it's the best." But she will warn her daughter, if she does get pregnant, about the potential harms of ringed seal liver. "I would just tell her, 'this is what could happen'. I'm not going to recommend that she doesn't eat it, I'm just going to tell her what effects there are," she said. (Murphy 2012)

Citing the Indigenous populations affected by the risk could provide a better understanding of the issue and how a hazard may impact a population (Clyne \& Clyne 1996).

There were also few articles that cited public health officials as an information source. Not citing health professionals misses the opportunity to include the perspectives of those with the training, role and responsibility of interpreting and communicating information about mercury contamination to the public. The lack of news stories that cited Indigenous populations or health officials indicates that there may be a need for connections between these populations/groups and journalists. There may be value in the development of tools or education centres to facilitate these connections in order for journalists to connect to northern voices or health officials. The facilitation of connections may help in other ways as there are likely numerous barriers for contact between northern 
populations and southern journalists. These barriers may include things such as the absence of an established relationship, issues with language and translation and access to reliable communications infrastructure. The capacity to connect journalists with affected populations and public health officials may help not only with the issue of contaminants and health but also with numerous other health and environmental issues in the Arctic.

\section{Conclusion}

There is comparatively little news coverage about mercury contamination in the Canadian Arctic. This may contribute to the lack of public awareness of the issue among those who are primarily affected by mercury contamination (i.e., Arctic residents) and those who also may be able to impact policy and public discourse on the issue (i.e., Arctic and southern Canadian residents). Other studies indicate that there is a lack of awareness about contaminants in the Arctic among northern populations (Myers \& Furgal 2006). Gaining a better understanding of how information about contaminants is presented to people through the media can help the public health community understand and anticipate challenges in communicating about mercury exposure. This information can provide an understanding of how a risk is being described and help public health officials determine what additional material may be needed to supplement media depictions of the hazard (Driedger et al. 2009).

While this research provides insight into how the media presents the risk of mercury contamination, there are some limitations to this study. The first limitation of this study is the inability to distinguish between the northern newspapers produced by the Northern News Services, as all archives were housed together. Second, as with all media analyses, newspaper archives may not be complete (Hansen \& Paul 2015). Finally, another limitation to this study is the lack of understanding of what media Canadian Arctic populations use to seek information about health risks and the fact that sources of information may vary across regions. For example, a study of residents in the communities of N'Dilo and Dettah in the Northwest Territories found that $56 \%$ of participants used newspapers to find information about health risks, whereas only $30 \%$ of participants from the communities of Hopedale and Nain in Nunatsiavut used newspapers to find information about health risks (Boyd et al. 2011). Further studies need to examine current methods that Canadian Arctic Indigenous populations use to consume health information and through what methods they prefer to receive information about health risks. It is important to note that we do not recommend that newspapers be the primary form of health communication in the Arctic. In most newspapers, the dominant language for presenting news is English and only a few newspapers in the northern regions (e.g., Kivalliq News, Nunuvut News/North and Nunatsiaq News) translate information into Indigenous languages and regional or local dialects. This is problematic because not all residents read the English language.

This research also provides avenues for additional future studies. Researchers should examine the potential roles Indigenous people and communities, journalists and health care providers play in providing information through news media and educating both the northern and southern Canadian populations about Arctic health risks. Interviews with these populations could explore how they see their role in educating the public, and how they would best engage with the general Canadian population, as well as affected populations in the North.

Additional research could also examine other contaminants (e.g., polychlorinated biphenyls, cadmium and lead) that disproportionately affect those residing in Arctic regions. Future studies should examine how mercury and other contaminants or "invisible" risks are communicated to the public to provide additional lessons learned and insights into techniques used to better communicate about contaminants, including who should present this information, where advisories need to be located and how health officials should discuss the risks to local populations.

\section{Disclosure statement}

The authors report no conflict of interest.

\section{Funding}

Funding for this study was provided by the Northern Contaminants Program of the Department of Indigenous Affairs and Northern Development.

\section{References}

Altheide D.L. \& Schneider C.J. 2013. Qualitative media analysis. Newbury Park, CA: Sage.

American Public Health Association 2011. Climate change: mastering the public health role. Accessed on the internet at https://www.apha.org on 10 November 2017.

AMAP (Arctic Monitoring and Assessment Programme) 2011. Arctic Monitoring and Assessment Programme assessment 2011: mercury in the Arctic. Accessed on the internet at https://oaarchive.arctic-council.org/handle/11374/1063 on 10 December 2016. 
Anctil M. 2008. Survey highlights. Nunavik Inuit Health Survey 2004, Qanuippitaa? How are we? Quebec: Institut National de Santé Publique du Québec \& Nunavik Regional Board of Health and Social Services.

Angler M.W. 2017. Science journalism: an introduction. London: Routledge.

Anonymous 2011. Deadly form of mercury found in Arctic waters: researchers. Nunatsiaq News, 28 April.

Bandura A. 1977. Self-efficacy: toward a unifying theory of behavioral change. Psychological Review 84, 191-215.

Bandura A. 1997. Self-efficacy: the exercise of control. London: Macmillan Publishing.

Blanchet C. 2008. Qanuippitaa? How are we? Nutrition and food consumption among the Inuit of Nunavik. Institut National de Santé Publique du Québec. Accessed on the internet at https://www.inspq.qc.ca/pdf/publications/762_ESI_Nutrition_Report_MA.pdf on 15 December 2016.

Boyd A.D., Jardine C.G. \& Furgal C. 2011. Communicating health risks in aboriginal communities: preferences and trust in information sources. Paper presented at the Annual Meeting of the Society for Risk Analysis, 4-7 December, Baltimore, MD.

Brodie M., Kjellson N., Hoff T. \& Parker M. 1999. Perceptions of Latinos, African Americans, and Whites on media as a health information source. Howard Journal of Communication 10, 147-167, http://dx.doi.org/10.1080/106461799246799.

Chan L. 2011. Inuit Health Survey 2007-2008: contaminant Assessment in Nunavut. Accessed on the internet at https://www.tunngavik.com/files/2012/06/IHS_Report_ Nunavut-English-Final.pdf on 13 November 2016.

Clyne M. \& Clyne M.G. 1996. Inter-cultural communication at work: cultural values in discourse. Cambridge: Cambridge University Press.

Collins P.A., Abelson J., Pyman H. \& Lavis J.N. 2006. Are we expecting too much from print media? An analysis of newspaper coverage of the 2002 Canadian healthcare reform debate. Social Science o Medicine 63, 89-102, http:// dx.doi.org/10.1016/j.socscimed.2005.12.012.

Corbett J.B. \& Durfee J.L. 2004. Testing public (un) certainty of science: media representations of global warming. Science Communication 26, 129-151, http://dx.doi.org/10.1177/ 1075547004270234.

Council of Canadian Academies 2014. Aboriginal food security in northern Canada: an assessment of the state of knowledge. Ottawa: Expert Panel on the State of Knowledge of Food Security in Northern Canada, Council of Canadian Academies.

De Kayser J., Raeymaeckers K. \& Paulussen S. 2010. Are citizens becoming sources? In B. Franklin \& M. Carlson (eds.): Journalists, sources, and credibility: new perspectives. Pp. 139-148. New York: Routledge.

Donaldson S.G., Van Oostdam J., Tikhonov C., Feeley M., Armstrong B., Ayotte P., Boucher O., Bowers W., Chan L. \& Dallaire F. 2010. Environmental contaminants and human health in the Canadian Arctic. Science of the Total Environment 408, 5165-5234, http://dx.doi.org/10.1016/j. scitotenv.2010.04.059.

Driedger S.M., Cynthia C.G., Boyd A.D. \& Mistry B. 2009. Do the first 10 days equal a year? Comparing two
Canadian public health risk events using the national media. Health, Risk $\theta$ Society 11, 39-53, http://dx.doi. org/10.1080/13698570802537011.

Dunwoody S. 1992. The media and public perceptions of risk: how journalists frame risk stories. In D. Bromley \& K. Segerson (eds.): The social response to environmental risk. Pp. 75-100. Norwell, MA: Kluwer Academic.

Egeland G. 2010. Inuit Health Survey 2007-2008. Nunavut. Nunavut Steering Committee. Accessed on the internet at https://www.mcgill.ca/cine/files/cine/adult_report_nunavut.pdf on 15 November 2016.

EPA (US Environmental Protection Agency) 2016. Health effects of exposures to mercury. Accessed on the internet at https://www.epa.gov/mercury/health-effects-exposuresmercury on 10 November 2016.

Ferguson D.L. 2005. Journalism today. New York: McGraw Hill Publishing.

Fleras A. 2003. Mass media communication in Canada. Scarborough: Thomas Nelson.

Friedman S.M. \& Dunwoody S. 1999. Communicating uncertainty: media coverage of new and controversial science. Mahwah, NJ: Lawrence Erlbaum Associates.

Furgal C., Powell S. \& Myers H. 2005. Digesting the message about contaminants and health in the Canadian north: review and recommendations for future research and action. Arctic 58, 103-1 14, http://dx.doi.org/10.14430/arctic404.

George J. 2015. Global action needed on Arctic contaminants: new human health report. Nunatsiaq News, 9 June. Accessed on the internet at http://nunatsiaq.com/stories/article/ 65674global_action_needed_to_curb_contaminants_in_ the_arctic_new_human_heal/ on 26 October 2018.

Government of Canada 2019. Canada and circumpolar Arctic. Accessed on the internet at http://www. canadainternational.gc.ca on 9 October 2019.

Green J. 2004. The contribution of a print media analysis to a public health response to Ross River virus. Australian and New Zealand Journal of Public Health 28, 296, http://dx.doi. org/10.1111/j.1467-842X.2004.tb00710.x.

Greenberg J. 2002. Framing and temporality in political cartoons: a critical analysis of visual news discourse. The Canadian Review of Sociology 39, 181-198, http://dx.doi. org/10.1111/j.1755-618X. 2002.tb00616.x.

Greiner A., Smith K.C. \& Guallar E. 2010. Something fishy? News media presentation of complex health issues related to fish consumption guidelines. Public Health Nutrition 13, 1786-1794, http://dx.doi.org/10.1017/S13689800 10000923.

Griffin R.J. \& Dunwoody S. 1997. Community structure and science framing of news about local environmental risks. Science Communication 18, 362-384, http://dx.doi.org/10.11 77/1075547097018004005.

Guest G., Bunce A. \& Johnson L. 2006. How many interviews are enough? An experiment with data saturation and variability. Field Methods 18, 59-82, http://dx.doi.org/1 $0.1177 / 1525822 X 05279903$.

Hansen K.A. \& Paul N. 2015. Newspaper archives reveal major gaps in digital age. Newspaper Research Journal 36, 290-298, http://dx.doi.org/10.1177/0739532915600745. 
Hodgetts D., Chamberlain K., Scammell M., Karapu R. \& Waimarie Nikora L. 2008. Constructing health news: possibilities for a civic-oriented journalism. Health 12, 43-66, http://dx.doi.org/10.1177/1363459307083697.

Indigenous and Northern Affairs Canada 2016. Indigenous peoples. Accessed on the internet at http://www.aadnc-aandc.gc.ca/eng/ on 13 November 2016.

Institute of Medicine 2003. The future of the public's health in the 21st century. Washington, DC: National Academies Press.

Jardine C.G., Boerner F.U., Boyd A.D. \& Driedger S.M. 2015. The more the better? A comparison of the information sources used by the public during two infectious disease outbreaks. PLoS One 10, e0140028, http://dx.doi. org/10.1371/journal.pone.0140028.

Judd N.L., Drew C.H., Acharya C., Marine Resources for Future Generations, Mitchell T.A., Donatuto J.L., Burns G.W., Burbacher T.M. \& Faustman E.M. 2005. Framing scientific analyses for risk management of environmental hazards by communities: case studies with seafood safety issues. Environmental Health Perspectives 113, 1502-1508, http://dx.doi.org/10.1289/ehp.7655.

Kinloch D., Kuhnlein H. \& Muir D.C. 1992. Inuit foods and diet: a preliminary assessment of benefits and risks. Science of the Total Environment 122, 247-278, http://dx.doi. org/10.1016/0048-9697(92)90249-R.

Kreuter M.W. \& McClure S.M. 2004. The role of culture in health communication. Annual Review of Public Health 25, 439-455.

Krümmel E.M. \& Gilman A. 2016. An update on risk communication in the Arctic. International Journal of Circumpolar Health 75, article no. 33822, http://dx.doi.org/10.3402/ ijch.v75.33822.

Kuhnlein H.V., Receveur O., Soueida R. \& Egeland G.M. 2004. Arctic Indigenous peoples experience the nutrition transition with changing dietary patterns and obesity. The Journal of Nutrition 134, 1447-1453.

Kurpius D.D. 2002. Sources and civic journalism: changing patterns of reporting? Journalism $\theta$ Mass Communication Quarterly 79, 853-866, http://dx.doi.org/10.1177/ 107769900207900406.

Lambden J., Receveur O., Marshall J. \& Kuhnlein H. 2006. Traditional and market food access in Arctic Canada is affected by economic factors. International Journal of Circumpolar Health 65, 331-340, http://dx.doi.org/10.3402/ ijch.v65i4.18117.

Lawn J. \& Harvey D. 2001. Change in nutrition and food security in two Inuit communities, 1992 to 1997. Ottawa: Department of Indian Affairs and Northern Development.

Lemire M., Kwan M., Laouan-Sidi A.E., Muckle G., Pirkle C., Ayotte P. \& Dewailly E. 2015. Local country food sources of methylmercury, selenium and omega-3 fatty acids in Nunavik, northern Quebec. Science of the Total Environment 509, 248-259, http://dx.doi.org/10.1016/j. scitotenv.2014.07.102.

Lougheed T. 2010. The changing landscape of Arctic traditional food. Environmental Health Perspectives 118, A386-A393, http://dx.doi.org/10.1289/ehp.118-a386.
Lundgren R.E. \& McMakin A.H. 2013. Risk communication: a handbook for communicating environmental, safety and health risks. Hoboken, NJ: John Wiley \& Sons.

MacKendrick N.A. 2010. Media framing of body burdens: precautionary consumption and the individualization of risk. Sociological Inquiry 80, 126-149, http://dx.doi. org/10.1111/j.1475-682X.2009.00319.x.

Maier S.R., Slovic P. \& Mayorga M. 2017. Reader reaction to news of mass suffering: assessing the influence of story form and emotional response. Journalism 18, 1011-1029, http://dx.doi.org/10.1177/1464884916663597.

Mazur A. 1981. Media coverage and public opinion on scientific controversies. Journal of Communication 31, 106-115, http://dx.doi.org/10.1111/j.1460-2466.1981.tb01234.x.

McAuley C. \& Knopper L.D. 2011 . Impacts of traditional food consumption advisories: compliance, changes in diet and loss of confidence in traditional foods. Environmental Health 10, article no. 55, http://dx.doi.org/10.1186/1476069X-10-55.

McCombs M.E. \& Shaw D.L. 1993. The evolution of agenda setting research: twenty-five years in the marketplace of ideas. Journal of Communication 43, 58-67, http://dx.doi. org/10.1111/j.1460-2466.1993.tb01262.x

McHugh M.L. 2012. Interrater reliability: the kappa statistic. Biochemia Medica 22, 276-282.

McMilliam E. 2010. Mercury rising? Lakes around Yellowknife not being tested for toxic substance. Northern News Services, 9 July.

McQuail D. 2002. Reader in mass communication theory. London: Sage.

Miles M.B. \& Huberman A.M. 1994. Qualitative data analysis. Thousand Oaks, CA: Sage.

Murphy D. 2012. High mercury levels prompt health advisory in Nunavut. Nunatsiaq News, 29 June.

Myers H. \& Furgal C. 2006. Long-range transport of information: are Arctic residents getting the message about contaminants? Arctic 59, 47-60.

Neuwirth K., Dunwoody S. \& Griffin R.J. 2000. Protection motivation and risk communication. Risk Analysis 20, 721-734, http://dx.doi.org/10.1111/0272-4332.205065.

Newig J. 2004. Public attention, political action: the example of environmental regulation. Rationality and Society 16, 149-190, http://dx.doi.org/10.1177/1043463104043713.

Niederdeppe J. \& Levy A. 2007. Fatalistic beliefs about cancer prevention and three prevention behaviors. Cancer Epidemiology, Biomarkers and Prevention 16, 998-1003, http://dx. doi.org/10.1158/1055-9965.EPI-06-0608.

Nucci M. \& Kubey R. 2007. “We begin tonight with fruits and vegetables": genetically modified food on the evening news. Science Communication 29, 147-176, http://dx.doi. org/10.1177/1075547007308173.

Nunavik Regional Board of Health and Social Services 2011. Healthy eating. Accessed on the internet at https://nrbhss. ca/en/departments/public-health/prevention-and-healthpromotion/healthy-eating\#healthy-eating on 15 December 2016.

NWT (Northwest Territories Government) 2007-2012. Advisories. Accessed on the internet at https://www.hss.gov. 
nt.ca/sites/hss/files/fish-consumption-notice-ekali-lake. pdf on 15 December 2016.

NWT (Northwest Territories Government) 2016. Fact sheet on public health and mercury. Accessed on the internet at https://www.hss.gov.nt.ca/sites/hss/files/resources/contaminants-fact-sheets-mercury.pdf on 10 December 2016.

Pincus R. \& Ali S.H. 2016. Have you been to 'the Arctic'? Frame theory and the role of media coverage in shaping Arctic discourse. Polar Geography 39, 83-97, http://dx.doi. org/10.1080/1088937X.2016.1184722.

Pirkle C.M., Peek-Ball C., Outerbridge E. \& Rouja P.M. 2015. Examining the impact of a public health message on fish consumption in Bermuda. PLoS One 10, e0139459, http:// dx.doi.org/10.1371/journal.pone.0139459.

Regidor E., de la Fuente L., Gutiérrez-Fisac J.L., de Mateo S., Pascual C., Sánchez-Payá J. \& Ronda E. 2007. The role of the public health official in communicating public health information. American Journal of Public Health 97, S93-S97, http://dx.doi.org/10.2105/AJPH.2006.094623.

Rogers S. 2011 . Eat more country foods: Nunavik health officials. Nunatsiaq News, 7 October.

Rothman A.J. \& Salovey P. 1997. Shaping perceptions to motivate healthy behavior: the role of message framing. Psychological Bulletin 121, 3-19, http://dx.doi.org/10.1037/ 0033-2909.121.1.3.

Sandman P.M. 1993. Responding to community outrage: strategies for effective risk communication. Fairfax, VA: American Industrial Hygiene Association.

Scheufele D.A. \& Tewksbury D. 2007. Framing, agenda setting, and priming: the evolution of three media effects models. Journal of Communication 57, 9-20, http://dx.doi. org/10.1111/j.1460-2466.2006.00326.x.

Schwitzer G., Mudur G., Henry D., Wilson A., Goozner M., Simbra M., Sweet M. \& Baverstock K.A. 2005. What are the roles and responsibilities of the media in disseminating health information? PLoS Medicine 2, e215, http://dx.doi. org/10.1371/journal.pmed.0020215.

Slovic P. 2000. The perception of risk. Sterling, VA: Earthscan.
Slovic P., Västfjäll D., Erlandsson A. \& Gregory R. 2017. Iconic photographs and the ebb and flow of empathic response to humanitarian disasters. Proceedings of the National Academy of Sciences 114, 640-644, http://dx.doi.org/10.1073/pnas. 1613977114.

SPJ (Society of Professional Journalists) 2014. Society of Professional Journalists Code of Ethics. Accessed on the internet at https://www.spj.org/ethicscode.asp on 26 October 2018.

Sprague D., LaVallie D.L., Wolf F.M., Jacobsen C., Sayson K. \& Buchwald D. 2011 . Influence of graphic format on comprehension of risk information among American Indians. Medical Decision Making 31, 437-443, http://dx.doi.org/10. $1177 / 0272989 X 10391096$.

UNEP (United Nations Environment Programme) 2013. Global mercury assessment: sources, emissions, releases and environmental transport. Accessed on the internet at http://wedocs.unep.org/bitstream/handle/20.500.11822/ 7984/-Global\%20Mercury\%20 Assessment-201367. pdf? sequence $=38$ isAllowed $=y$ on 10 December 2016.

Usher P.J., Baike M., Demmer M., Nakashima D., Stevenson M. \& Stiles M. 1995. Communicating about contaminants in country food: the experience in aboriginal communities. Ontario: Research Department, Inuit Tapirisat of Canada.

Van Oostdam J., Donaldson S.G., Feeley M., Arnold D., Ayotte P., Bondy G., Chan L., Dewaily E., Furgal C.M. \& Kuhnlein H. 2005. Human health implications of environmental contaminants in Arctic Canada: a review. Science of the Total Environment 351, 165-246, http://dx.doi. org/10.1016/S0048-9697(99)00036-4.

Weiner I.B. \& Craighead W.E. 2010. The Corsini encyclopedia of psychology. Hoboken, NJ: John Wiley \& Sons.

Yzer M. 2012. Perceived behavioral control in reasoned action theory a dual-aspect interpretation. The Annals of the American Academy of Political and Social Science 640, $101-111$.

Zarate G. 2010. Researchers hope Arctic char hold key to mercury mystery. Nunatsiaq News, 24 August. 